\title{
Self-regulated learning: A key learning effect of feedback in a problem-based learning context
}

\author{
A G Mubuuke, BSc, MSc, MPhil, PhD Fellow; A J N Louw, PhD; S van Schalkwyk, PhD \\ Centre for Health Professions Education, Faculty of Medicine and Health Sciences, Stellenbosch University, Cape Town, South Africa
}

Corresponding author: A G Mubuuke (gmubuuke@gmail.com)

Background. Problem-based learning (PBL) has been adopted across many health professions training institutions. Small-group student tutorials are a major component of PBL. Facilitator feedback during a tutorial is a key activity to promote self-regulated learning.

Objective. To explore ways in which students use feedback to promote self-regulated learning in a PBL environment.

Methods. This was an exploratory qualitative study in which individual interviews and focus group discussions were conducted with health science students who had experience of the tutorial process. Data were collected through audio recording and writing of field notes. Thematic analysis was employed to generate the reported themes.

Results. Students used feedback in various ways that can lead to self-regulated learning. Their experiences were summarised into three themes, i.e. activation of prior knowledge; reflection; and formulation of a personal learning plan. From the findings, a conceptual model linking feedback and selfregulated learning in a PBL context was developed.

Conclusion. In this study, we propose a conceptual model illustrating how feedback is a major activity in the critical pathway that leads to self-regulated learning.

Afr J Health Professions Educ 2017;9(1):34-38. DOI:10.7196/AJHPE.2017.v9i1.715

Following its initial conception at McMaster Medical School, ${ }^{[1]}$ problem-based learning (PBL) has been adopted by many health professions institutions. ${ }^{[2]}$ PBL is preferred, because it fosters student-centred learning compared with traditional didactic teacher-centred lectures. ${ }^{[3]}$ It allows students to construct new knowledge based on previous knowledge through regulation of their own learning. The focus of PBL is the tutorial process, which allows students to take control of their own learning. ${ }^{[3]}$ During this tutorial process, a small group of students meet and discuss a given learning task, which can take on many forms, such as a written problem, clinical case scenario, or clinical vignette. This task stimulates the students' discussion, thereby acting as a trigger for learning.

During the tutorial process, the lecturer facilitates the students' discussion to ensure that it is aligned to the institutional learning objectives, ${ }^{[4]}$ ensuring that students understand the concepts of the problem and formulating appropriate learning objectives, which subsequently guide their self-directed independent study. In PBL, therefore, the role of the lecturer (who in the tutorial is called a tutor) is to guide students and promote sharing, interaction and exchange of ideas towards constructing new knowledge. ${ }^{[4]}$

Learning in a PBL tutorial group is aimed at enhancing activation of prior knowledge, elaboration of such knowledge, and discovering new knowledge to build on prior knowledge through students' own self-directed and selfregulated learning processes. ${ }^{[3,4]}$ Self-regulated learning has been described as learning where students use various mechanisms to take control of their own learning processes. ${ }^{[5]}$ They are proactive, and they direct and control their own learning.

Zimmerman ${ }^{[5]}$ reports that students' achievements cannot only be attributed to abilities, but that skills to participate in self-regulated learning also contribute. Zimmerman and Schunk ${ }^{[6]}$ as well as Zimmerman ${ }^{[5]}$ further report that in self-regulated learning, students should be active participants in learn- ing rather than passive recipients of knowledge, tenets that are evident within a PBL tutorial. Other studies have shown that students' interest in a subject influences their self-regulation. ${ }^{[7,8]}$ For example, students who are highly interested in a subject are likely to use efficient self-regulatory strategies to learn independently, even in the absence of tutors.

During the process of guiding students in a PBL tutorial, the tutor delivers feedback, identifying strengths, as well as learning gaps that need to be addressed. Feedback has been described as the exchange of information by human beings in a problem-solving situation. ${ }^{[9]}$ In the context of this study, it can be viewed as the exchange of information between tutors and students regarding performance during PBL tutorials.

Feedback acknowledges students' progress in relation to achieving the intended learning objectives. ${ }^{[9]}$ By providing an opportunity for students to reflect and act upon the received feedback, tutors indirectly facilitate not only students' learning, but also their self-regulated learning skills. ${ }^{[9]}$ Therefore, effective feedback has been defined as being concise, clear, specific and timely and identifies learning strengths and gaps. ${ }^{[9]}$ Butler and Winne ${ }^{[10]}$ link the concepts of feedback and self-regulation. They described self-regulated learners as those who possess skills of setting goals to acquire knowledge, and discuss strategies to address these goals while monitoring, evaluating and reflecting upon the process, sometimes re-shaping their initial goals to achieve their objectives. During this entire process of self-regulation, Butler and Winne ${ }^{[10]}$ conclude that 'feedback is an inherent catalyst'.

Pintrich $^{[11]}$ further reports that self-regulation is an 'active constructive process whereby learners set goals for their learning and then attempt to monitor, regulate, and control their cognition, motivation, and behavior, guided by their goals' The concepts of self-regulation reported by Butler and Winne ${ }^{[10]}$ and Pintrich ${ }^{[11]}$ are evident in a typical PBL tutorial process, where feedback is an integral part. Hattie and Timperley ${ }^{[12]}$ concur that self- 
regulation is vital to effective learning, and that feedback offers an opportunity to students to practise self-regulated learning.

Self-regulated learning theory was advanced by Pintrich. ${ }^{[11]}$ It comprises four phases of self-regulation, including: (i) forethought, planning and activation; (ii) monitoring; (iii) control; and (iv) reaction and reflection. These phases of self-regulated learning are also evident in a PBL tutorial. The theory emphasises that with self-regulation, learners: (i) should be active participants in the learning process; (ii) have the potential to control key learning activities; (iii) have goals against which to assess progress; and (iv) mediate personal factors and performance outcomes.

From the literature, one can identify that self-regulated learning can be achieved within a PBL context, as it is a student-centred instructional approach. One can also identify that feedback of performance with regard to learning tasks has the potential of promoting self-regulated learning. However, a key question arises, i.e. how do students utilise feedback received within the PBL environment to promote self-regulated learning? This question formed the basis of this study.

\section{Methods}

\section{Study setting}

The study was conducted at the College of Health Sciences, Makerere University, Kampala, Uganda.

The institution trains undergraduate students across various health disciplines using a PBL approach. Small-group tutorials of $\sim 8-10$ students are conducted twice a week, facilitated by a tutor, who also delivers feedback to students.

\section{Research design}

This was an exploratory qualitative study. This kind of design allowed an in-depth understanding of a subject from the perspective of participants. ${ }^{[13]}$ Adopting this study design was aimed at obtaining an in-depth insightful understanding of how students used feedback to engage in self-regulated learning in a PBL tutorial context.

\section{Study participants}

Purposive sampling was used to select the student participants. These included 3rd-year undergraduate health science students across five disciplines: medicine, dentistry, radiography, pharmacy and nursing. Third-year students were chosen because they attend tutorials within their specific professional disciplines and were not integrated. In total, 25 individual interviews and five focus group discussions were conducted. Each focus group consisted of 6 - 8 students.

\section{Data collection and management}

Data were collected during in-depth individual interviews and focus group discussions. The interview sessions and focus group discussions were conducted in English. Questions used to guide the interviews and focus group discussions were open-ended and semi-structured, which allowed participants to freely express their experiences without being directed. The development of these questions was informed by the literature and generally explored ways in which students used feedback to engage in self-regulated learning. The questions for both the individual interviews and focus group discussions were first piloted to assess clarity. Using two methods of collecting data was for purposes of triangulation. Responses from the participants were audio recorded and later transcribed. The transcribed data were put into electronic format and stored on one computer secured by a password. These data were accessible only to the researchers.

\section{Data analysis}

Thematic analysis was used. Analysis was carried out manually by the researchers. Raw data were read and through a series of iterative and inductive open and axial coding, codes were developed. This involved reading through the participants' responses, identifying common meanings and coding them. Specific codes were developed, related to each other to generate broader categories of similar responses. These were also related to each other and to the raw data, subsequently resulting in major themes that were used to report findings.

\section{Quality assurance}

Participants were invited to validate emerging themes. Furthermore, researcher bias was minimised by having more than one researcher; they avoided all preconceived ideas or experiences of the subject under investigation, thus practising reflexivity and bracketing throughout the research process. The researchers engaged in the research process with an open mind and did not impose their own views and ideas on the participants. Using more than one data collection method also added rigour to this study, and thus improved quality of the data collected.

\section{Ethical considerations}

Participants provided written informed consent, and their anonymity and confidentiality were ensured. Permission to conduct the study was granted by the Health Research Ethics Committee, Faculty of Medicine and Health Sciences, Stellenbosch University, Cape Town, South Africa, and the Research and Ethics Committee, School of Medicine, College of Health Sciences, Makerere University, Kampala, Uganda (ref. no. S15/04/071).

\section{Results}

The purpose of this study was to explore how students used tutor feedback received in a PBL tutorial to engage in self-regulated learning practices. Various ways in which students used feedback to become self-regulated learners were identified. These have been grouped into three themes, presented below:

\section{Theme 1: Activation of prior knowledge}

Students used feedback to activate their prior knowledge, recalling what they knew about the learning task from accumulated learning experiences. The following were typical responses:

'I always used feedback from my tutor to try and link up the concepts that I already knew from my high school to solve the learning tasks given to me ... ? (Medicine student)

'The PBL problems sometimes looked very knew to me and at first, I could not figure out how to tackle them. However, I realised that the tutor feedback reminded me of certain concepts I had learnt from previous problems which I recalled. This helped a lot ... to drive my understanding.' (Radiography student)

'Many PBL cases especially in first year were actually related to my high school concepts ... even second year cases were related to first year cases. I therefore had to recall most of that data ... the tutor feedback was vital in this recall process because the tutor would give us trigger responses and questions which enabled us to recall the already learnt information .... ? (Nursing student)

'The tutor feedback assisted me to recall many concepts I had already learnt. I had forgotten them and yet they were applicable to the new PBL 
case ... this is why tutors should attend all our tutorials ... their feedback helps us a lot.' (Pharmacy student)

From the responses above, one can observe that tutor feedback in the form of triggers, challenging observations, comments and questions in a PBL tutorial enabled students to recall information acquired from previous experiences and apply it to solve a current learning task.

\section{Theme 2: Reflection}

Students used feedback to reflect on their own performance. From numerous responses, this reflection seemed to centre around self-appraisal regarding competency, using feedback received, discovering strengths and identifying learning gaps that still needed to be addressed. The following responses were a common thread:

'The feedback I received from my tutors often helped to critique my own contribution to the tutorial discussion because from this feedback, I would discover where I did best and where I needed to improve. Without this feedback ... I would not consider some aspects probably'. (Dentistry student)

'I think the beauty with our PBL tutorial feedback is that it engages one to appraise oneself regarding mastery of the concepts in the tutorial problem. Personally, I used to find it hard to internally evaluate myself objectively. With tutor feedback, it is easy for me to use those comments, look at what he said I did well and what I did not do well ... and this pushes me to work even harder to cover my gaps.' (Medicine student)

'The biggest strength of this feedback process in the tutorial is that it teaches you how to self-evaluate your own work. The comments generated by the tutor are so important in guiding us on where we need to maintain and also improve. It teaches us to critically think about our work and gauge our own performance.' (Radiography student)

'The tutors have always been talking about reflection about our work, but they had failed to teach us how to reflect effectively. The feedback I get from my tutor has actually done the trick. I use the comments from my tutor to evaluate myself and reflect upon my own performance ... this helps me a lot ... all tutors should give us good feedback. It is better than preparing a power point lecture teaching me how to reflect.' (Pharmacy student)

The responses set out above illustrate how tutor feedback enhanced reflective practice. It seemed that feedback played a crucial role in directing the students to practise reflection and self-appraisal regarding their performance, identifying both strengths and areas that needed improvement.

\section{Theme 3: Formulation of a personal learning plan}

Students used feedback to design their own learning plans. The identified learning gaps became their learning objectives. From the responses obtained, the feedback appeared to assist students to clearly identify and formulate learning objectives that would guide their self-study, organise and plan for adequate time frames to cover objectives, identify key knowledge sources to obtain information that would address the learning objectives, and then apply new knowledge gained to fully solve the learning task. The following responses were typical:
'The feedback we received in our groups was very instrumental in helping us form our learning objectives. It is these objectives that guided our selfdirected learning.' (Nursing student)

'To me, the tutor feedback assisted me to identify my knowledge gaps and this gave me an opportunity to plan on how to discover that knowledge and where to get it from. Most likely without such feedback, my learning would not have been directed effectively.' (Dentistry student)

'I think the overall advantage I see with tutor feedback is that it enables students to identify from tutor comments what they have done well and what they need to improve upon. Areas that need improvement then become our learning objectives that direct our self-study. With such objectives formulated, I can then draw up my own learning time frames and identify sources of information to cover the objectives.' (Medicine student)

\section{Discussion}

The purpose of this study was to explore ways in which students used tutor feedback received within a PBL tutorial to engage in self-regulated learning. There were no major variations in responses received from students across various health science disciplines. The reason for this observation is not clear-cut. A possible explanation could be that the students who participated were drawn from the same PBL environment, where they share the tutors and learning resources.

Tutor feedback prompted students to utilise key activities identified in this study to engage in self-regulated learning. These included: activation of prior knowledge, reflective practice, and formulation of personal learning plans. These can be linked to self-regulated learning theory, which emphasises activation of what is already known, as well as reflection. ${ }^{[11]}$ Therefore, PBL tutors need to be aware that feedback is vital in engaging students into selfregulated learning processes. Such feedback should therefore be packaged and delivered efficiently.

\section{Activation of prior knowledge}

Students in this study used feedback received from tutors to activate prior knowledge. This finding resonates well with what is postulated in self-regulated learning theory, i.e. activating prior knowledge activates self-regulated learning processes. ${ }^{[6,7]}$ Therefore, feedback could be one way of achieving this. Activation of student prior knowledge to solve PBL learning tasks has also been previously emphasised in the PBL literature. ${ }^{[4]}$ Gijbels et al. ${ }^{[2}$ reported that students possess much knowledge of previous learning experiences, and new learning tasks should build on what students already know. Effective PBL tutors should be able to invoke what students already know so that newly acquired knowledge builds on what is already known.

Good feedback in a PBL tutorial is one way of stimulating students to recall already acquired knowledge to solve new learning tasks. ${ }^{[3]}$ Our findings resonate well with these previous findings. It can be discerned from our study that tutor feedback helped students to recall concepts already learnt to solve new PBL learning tasks. The feedback probably also assisted students to place their knowledge in sequence, relating new information to what is already known. Therefore, good feedback delivery practice is one way through which tutors can assist students to recall already learnt knowledge, subsequently engaging them in self-regulated learning. This study did not specifically focus on exploring attributes of good feedback. However, one 
could notice that students perceived some feedback as beneficial, which implicitly reflected the attributes of good feedback reported in the literature. For example, students expressed that specific, clear and unambiguous feedback was significant in their learning. Specificity and clarity of feedback have been reported as some of the good feedback attributes. ${ }^{[12]}$

\section{Reflection}

Feedback also assisted students to reflect about performance. This finding is in agreement with what is reported in self-regulated learning theory, i.e. active reflection about performance promotes self-regulated learning. ${ }^{[7,8]}$ The importance of training reflective health professionals has been previously emphasised. ${ }^{[14]}$ This reflective practice is vital, as it helps health professionals to independently appraise their own performance, identifying strengths and areas that need improvement. ${ }^{[14]}$ Although the literature emphasises the importance of training students how to engage in reflective practice, ${ }^{[15]}$ there is a dearth of reported literature on how to teach reflection.

Findings from this study probably contribute to this gap. We identified that good tutor feedback in a PBL context could probably be one way through which students can be trained how to reflect. Such feedback should be specific, timely and clear. Feedback comments from tutors most likely trigger students to think about the task and their own performance of the task, and identify what they did well and where they need to improve. Students therefore engage in a form of self-evaluation, using the feedback received, which enhances their self-regulated learning.

\section{Formulation of a personal learning plan}

Feedback enabled students to form their personal learning plans. This finding relates well to self-regulated learning theory, which postulates that self-regulated learners always form personal learning goals against which to assess progress. ${ }^{[1]}$ Clearly forming a learning plan to address a learning task is a vital step in a PBL tutorial. A learning plan may include aspects such as forming learning objectives (which emanate from initially identified learning gaps) and mapping out key sources of information to address those objectives and subsequently solving the learning task. It is sometimes a challenge for students to suggest a clear learning plan from the tutorial; ${ }^{[1]}$ therefore, the tutor has a role to play by guiding students to create a clear learning plan.

While it is standard practice in PBL for students to derive their own learning objectives, they may not be able to satisfactorily achieve this, even when the tutor is present to guide them. Sometimes the tutor feedback may be inefficient in guiding students to derive good learning objectives. The key message in this study is that effective feedback from the PBL tutor regarding students' strengths and learning gaps with regard to the presented task and relating this feedback to the intended learning outcomes make this process easier. Therefore, while tutors may deliver feedback, it may not assist students to form their learning objectives. This feedback must follow good feedback principles to achieve this. If tutor feedback is inefficient, even though the tutor is present, students might struggle. Feedback that is specific, focused and clear assists students to only focus on those key areas pertinent to the PBL task and not digress into other irrelevant issues. Often, students without tutor guidance formulate learning objectives that are skewed away from the intended institutional learning outcomes. ${ }^{[4]}$

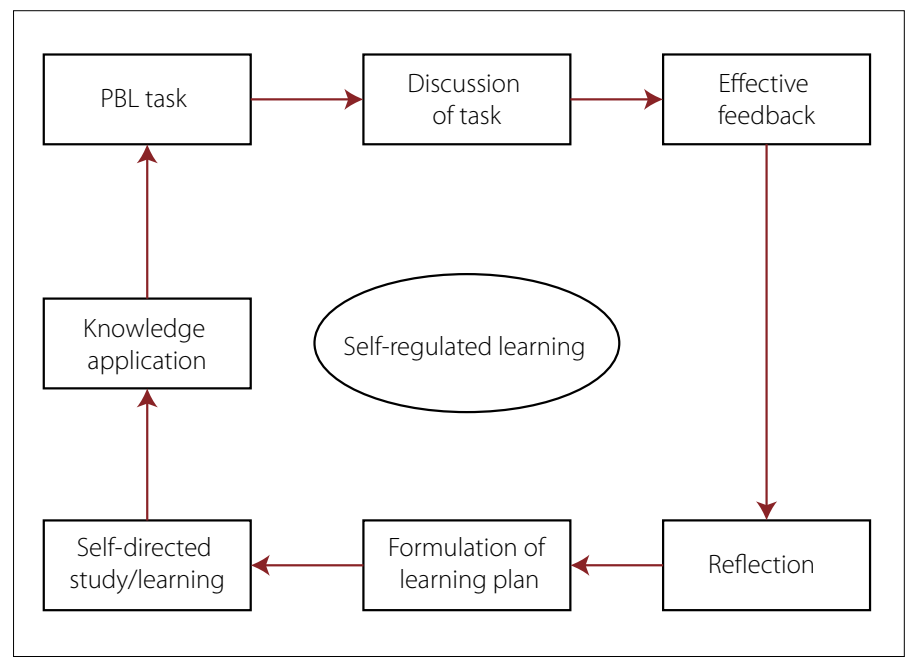

Fig. 1. A conceptual model relating feedback and self-regulated learning in a PBL tutorial.

\section{Feedback and self-regulated learning: A conceptual model}

From the preceding discussion, one can discern that tutor feedback in a PBL tutorial can probably assist students to take charge of their own learning through activation of prior knowledge, engagement in reflective practice, and formulation of personal learning plans to address any gaps that may exist. All these cognitive activities, driven by feedback, are part of selfregulated learning. Based on these findings, a conceptual model has been developed linking feedback and self-regulated learning within a PBL tutorial environment (Fig. 1). The model illustrates that good feedback is vital in the critical pathway towards training self-regulated learners.

The model postulates that self-regulated learning is central in a PBL tutorial setting, where students direct and plan their own learning. Various activities contribute to self-regulated learning. At first, there is an initial learning task, which then triggers active student discussion, activating prior knowledge to solve the task. Vital to this process is the feedback students receive from the PBL tutor regarding performance of the task. This feedback, which must follow good feedback principles, such as being timely, unambiguous and specific, ${ }^{[12]}$ then engages students in active reflection about the task and how they have solved it. It is therefore the feedback in the tutorial that initiates this process of reflection. During this reflective process, students identify learning gaps and formulate a learning plan to cover those gaps. The plan might include raising learning objectives, identifying knowledge sources, and putting in place time frames to cover the objectives before a new task is introduced.

With a learning plan, students then engage in self-directed study, where they use sources of knowledge already identified and tutor feedback to address the learning objectives of the task. Subsequently, students apply this newly acquired knowledge from self-directed study to not only cover the learning gaps of the initial PBL task, but also to solve future learning tasks. From the model one can observe that self-regulated learning within a PBL context involves many activities, of which tutor feedback is very vital. Each of these activities, evident within a PBL tutorial, contributes to promote self-regulated learning processes in students. 
Findings from this study are generally in agreement with the literature, which shows that feedback can promote self-regulated learning. What this study adds to the literature is how feedback promotes self-regulated learning in a PBL context. It has been observed from the study that tutor feedback promotes activation of prior knowledge, gives students an opportunity to engage in reflection, and formulate learning objectives that subsequently guide their selfdirected learning. This ultimately leads to self-regulated learning.

The study involved small numbers of student participants from one institution. This and the non-probability sampling technique are major study limitations. Although the focus was on students from one institution only, it is envisaged that involving many more students and other stakeholders, such as PBL tutors and feedback experts from more than one institution, would probably have added richness to the findings. The conceptual model developed from this study also presents new thinking and gives direction for future research in health professions education. This model was developed from one institution and therefore calls for its testing and validation in other settings, which is likely to give more insight on the issues raised within this framework.

\section{Conclusion}

This study demonstrated that tutor feedback assisted students to activate prior knowledge, engage in active reflection, and formulate their own learning plans - processes in self-regulated learning. Therefore, PBL tutors should be aware that self-regulated learning, which PBL aims to promote, is a key learning effect of effective feedback.

\footnotetext{
1. Schwartz P, Mennin S, Webb G. Problem-based Learning: Case Studies, Experience and Practice. London: Kogan Page, 2001

. Gijbels D, Dochy F, van den Bossche P, Segers M. Effects of problem-based learning: A meta analysis from the angle of assessment. Rev Educ Res 2005;71(1):27-61. http://dx.doi.org/10.3102/00346543075001027

3. Gukas ID. Problem-based learning in undergraduate medical education: Can we really implement it in the West African subregion? West Afr J Med 2007;26(2):87-92.

4. Savery JR. Overview of problem-based learning: Definitions and distinctions. Interdisc J Problem Based Learn 2006;1(1):9-20. http://dx.doi.org/10.7771/1541-5015.1002

5. Zimmerman BJ. Theories of self-regulated learning and academic achievement: An overview and analysis. In: Zimmerman BJ, Schunk DH, eds. Self-regulated Learning and Academic Achievement: Theoretical Perspectives 2nd ed. Mahwah, NJ: Lawrence Erlbaum Associates, 2001:1-38.

6. Zimmerman BJ, Schunk DH. Self-regulated Learning and Academic Achievement: Theoretical Perspectives. 2nd ed. Mahwah, NJ: Lawrence Erlbaum Associates, 2001

7. Pintrich PR, Zusho A. The development of academic self-regulation: The role of cognitive and motivational factors. In: Wigfield A, Eccles JS, eds. Development of Achievement Motivation. San Diego, CA: Academic 2002:249-284.

8. Yang M, Carless D. The feedback triangle and the enhancement of dialogic feedback processes. Teach Higher Educ 2013;18(3):285-297.

9. Orsmond P. Maw SI, Park IR Gomez S, Crook AC Moving feedback forward: Theory to practice. Assess Eval 9. Orsmond P, Maw S, Park JR, Gomez S, Crook AC. Moving feedback forward: The
Higher Educ 2013;38(2):240-252. http://dx.doi.org/10.1080/02602938.2011.625472

Higher Educ 2013;38(2):240-252. http://dx.doi.org/ $/ 10.1080 / 02602938.2011 .625472$
10. Butler DL Winne PH. Feedback and self-regulated learning: A theoretical synthesis. Rev Educ Res 1995;65(3):245-281. http://dx.doi.org/10.3102/00346543065003245

11. Pintrich PR. The role of goal orientation in self-regulated learning. In: Boekaerts M, Pintrich PR, Zeidner M, eds. Handbook of Self-regulation. San Diego, CA: Academic, 2000:451-502.

12. Hattie J, Timperley H. The power of feedback. Rev Educ Res 2007;77(1):81-112. http://dx.doi.org/ $10.3102 / 003465430298487$

13. Braun V, Clarke V. Using thematic analysis in psychology. Qual Res Psychol 2006;3(2):77-101. http://dx.do org $/ 10.1191 / 1478088706 q p 0630$

14. Mubuuke AG, Kiguli-Malwadde E, Kiguli S, Businge F. A student portfolio; the golden key to reflective, experiential and evidence-based learning. J Med Imaging Radiat Sci 2010;41(2):72-78. http://dx.doi.org/10.1016/j. jmir.2010.03.001

15. Hughes M, Heycox K. Promoting reflective practice with older people: Learning and teaching strategies. Aust
} Social Work 2005;58(4):344-356. http://dx.doi.org/10.1111/j.1447-0748.2005.00231.x 